\title{
Lusioersily
}

\section{Familiarization, validity and smallest detectable difference of the isometric squat test in evaluating maximal strength}

Drake, D., Kennedy, R., \& Wallace, E. S. (2018). Familiarization, validity and smallest detectable difference of the isometric squat test in evaluating maximal strength. Journal of Sports Sciences, 36(18), 2087-2095. [18]. https://doi.org/10.1080/02640414.2018.1436857

Link to publication record in Ulster University Research Portal

Published in:

Journal of Sports Sciences

Publication Status:

Published (in print/issue): 01/01/2018

DOI:

10.1080/02640414.2018.1436857

\section{Document Version}

Author Accepted version

\section{General rights}

Copyright for the publications made accessible via Ulster University's Research Portal is retained by the author(s) and / or other copyright owners and it is a condition of accessing these publications that users recognise and abide by the legal requirements associated with these rights.

\section{Take down policy}

The Research Portal is Ulster University's institutional repository that provides access to Ulster's research outputs. Every effort has been made to ensure that content in the Research Portal does not infringe any person's rights, or applicable UK laws. If you discover content in the Research Portal that you believe breaches copyright or violates any law, please contact pure-support@ulster.ac.uk. 
1 Manuscript Title: Familiarization, validity and smallest detectable difference of the

2 isometric squat test in evaluating maximal strength

3 Running Title: Validity of the isometric squat test

4

5 Keywords: strength trained, responsiveness, stability reliability, squat performance

6

7 Word Count: 3988

8

9 Authors: David Drake ${ }^{1,2^{*}}$, Rodney Kennedy ${ }^{1,3}$ and Eric Wallace ${ }^{1,3}$

10 Department/Institution: ${ }^{\mathbf{1}}$ School of Sport, Ulster University; ${ }^{2}$ Ulster Rugby, Irish

11 Rugby Football Union; ${ }^{3}$ Sport and Exercise Science Research Institute, Ulster

12 University

13 Corresponding Author Details*: School of Sport, Ulster University, Jordanstown,

14 Shore Road, Newtownabbey, Co. Antrim, BT37 0QB, N. Ireland.

15 Email: daviddrake87@gmail.com

16 Phone: +447442495722

17 Twitter:@d drakey

18 ORCID: orcid.org/0000-0003-0440-7097

19

20

Postal address (all authors): As per corresponding author.

23 Prof Eric Wallace: email es.wallace@ulster.ac.uk; phone +44 2890366535

27 Disclosure Statement: No external financial support was received for the

28 completion of this study. The authors have no conflicts of interest. 
30 Isometric multi-joint tests are considered reliable and have strong relationships with

31 1RM performance. However, limited evidence is available for the isometric squat in

32 terms of effects of familiarization and reliability. This study aimed to assess, the effect

33 of familiarization, stability reliability, determine the smallest detectible difference, and

34 the correlation of the isometric squat test with 1RM squat performance. Thirty-six

35 strength-trained participants volunteered to take part in this study. Following three

36 familiarization sessions, test-retest reliability was evaluated with a 48-hour window

37 between each time point. Isometric squat peak, net and relative force were assessed.

38 Results showed three familiarizations were required, isometric squat had a high level

39 of stability reliability and smallest detectible difference of $11 \%$ for peak and relative

40 force. Isometric strength at a knee angle of ninety degrees had a strong significant

41 relationship with $1 \mathrm{RM}$ squat performance. In conclusion, the isometric squat is a valid

42 test to assess multi-joint strength and can discriminate between strong and weak 1RM

43 squat performance. Changes greater than $11 \%$ in peak and relative isometric squat

44 performance should be considered as meaningful in participants who are familiar with

45 the test.

47 Keywords: strength-trained, responsiveness, stability reliability, squat performance 
55 Strength tests are used to determine an athlete's responsiveness to a training

56 program or current level of performance (Kraska et al., 2009). This information can

57 be utilized to prescribe optimal loading in athlete's training programs (Suchomel,

58 Nimphius, \& Stone, 2016). When determining maximum strength in athletes, the one

59 repetition maximum test (1RM) has traditionally been used (Appleby, Newton, \&

60 Cormie, 2012; Buckner et al., 2016; Loturco et al., 2016). Whilst the 1RM squat is

61 considered reliable (Comfort \& McMahon, 2015) the implementation of 1RM tests

62 can be challenging due to variability in methodological approaches to control range of

63 motion (McMaster, Gill, Cronin, \& McGuigan, 2014), the requirement for squatting

64 skill under a maximal external load (Ploutz-Snyder \& Giamis, 2001) and the lack of

65 practicality with novice, elderly or functionally limited participants (Jidovtseff, Harris,

66 Crielaard, \& Cronin, 2011). Regular 1RM testing can also take significant time away

67 from training (Banyard, Nosaka, \& Haff, 2017) with congested competition schedules

68 and large groups of players in team sports being further limitations to implementing

69 1RM tests (Loturco et al., 2016) within applied settings.

71 As an alternative to 1RM testing, isometric multi-joint tests (IMJT) are used to test

72 maximum strength and are considered easier to standardize than 1RM tests (Bazyler,

73 Beckham, \& Sato, 2015). Given IMJTs are easily controlled and have minimal skill

74 requirement (Wang et al., 2016), theoretically they could improve the reliability and

75 responsiveness of strength measurements and have greater practical impact for

76 coaches to interpret change over time. IMJTs are very strongly related to 1RM strength

77 performance (McGuigan, Newton, Winchester, \& Nelson, 2010; Suchomel et al.,

78 2016) and have been shown to discriminate between strong and weak athlete groups

79 (Bailey, Sato, Burnett, \& Stone, 2015a; Kraska et al., 2009; Thomas, Jones, Rothwell, 
80 Chiang, \& Comfort, 2015). IMJTs have also been utilized to assess acute fatigue

81 response to maximum strength training (Kennedy \& Drake, 2017; Storey, Wong,

82 Smith, \& Marshall, 2012) and are deemed appropriate to evaluate responsiveness over

83 time (Drake, Kennedy, \& Wallace, 2017).

85 Understanding reliability of strength testing is a key pillar to interpret the 86 responsiveness of athletes to training programs (Hopkins, 2004). The responsiveness

87 of a test is a crucial component of validity defined as, the ability of a test to detect

88 change over a time (Terwee et al., 2007). Responsiveness is best described with

89 respect to the smallest detectible difference (SDD) calculated based on a test-retest

90 study design (Beckerman et al., 2001). To determine the SDD, the length of time

91 between test-retest should be ecologically appropriate to assess the stability of the

92 variables of interest between tests (Comfort \& McMahon, 2015; Davidson \& Keating,

93 2014). This between day test-retest reliability is defined by Baumgarter (1989) as

94 stability reliability. Stability reliability assessments are preferential over between trial

95 designs as they account for systematic bias affecting performance tests (Atkinson \&

96 Nevill, 1998; Ritti-Dias, Avelar, Salvador, \& Cyrino, 2011; Taylor, Cronin, Gill,

97 Chapman, \& Sheppard, 2010). The implementation of stability reliability designs in

98 IMJT investigations are currently limited (Drake et al., 2017) therefore further work

99 is required to understand reliability and responsiveness.

100

101 Acknowledging the stability reliability investigations using the isometric mid-thigh

102 pull (Comfort, Jones, McMahon, \& Newton, 2015; Dos'Santos, Thomas, \& Oakley,

103 2017), we are aware of only one study using the isometric squat test (Palmer, Pineda,

$104 \&$ Durham, 2017) that enables the calculation of SDD. The study by Palmer et al. 
105 (2017) was conducted in female only participants thus limiting generalizability.

106 Despite the known effects of familiarization on isometric testing (Calder \& Gabriel,

107 2007; Dos'Santos et al., 2017; Maffiuletti et al., 2016) authors in the field continue to

108 not provide the measured effects of familiarization in IMJTs. Studies should evaluate

109 the familiarization effects rather simply stating that one session was completed (Brady,

110 Harrison, Flanagan, Haff, \& Comyns, 2017; Comfort et al., 2015; Palmer et al., 2017)

111 or that participants were familiarized (Dos'Santos et al., 2017) by providing measured

112 familiarization data.

113

114 Following a measured familiarization period, the purpose of this study was to (1)

115 assess the stability reliability of the isometric squat test in absolute and relative terms,

116 (2) determine the SDD to enable assessment of responsiveness, (3) assess the strength

117 of the relationship between the isometric squat test and the commonly assessed 1RM

118 back squat and (4) use the isometric squat to discriminate between strong vs weak

119 1RM back squat performers. It was hypothesized that the isometric squat would

120 demonstrate a high level of relative reliability (ICC $\geq .70$ ), low level of absolute error,

121 and strong-significant relationship with the dynamic criterion test $(r>.70)$.

122 Additionally, isometric squat performance would effectively discriminate between

123 strong vs weak 1RM squat performers.

125 Methods

126 Experimental Design

127 A within-subject repeated measures design was implemented to assess familiarization

128 and reliability of the isometric squat test. Three familiarization sessions were

129 conducted followed by test and retest reliability sessions, with 48 hours between each 
130 test. Familiarization sessions followed the procedures of the test and retest sessions

131 (provided in procedures section). A 1RM Squat test was completed post isometric

132 squat in the retest session. All testing sessions were standardized to the nearest hour

133 of the day from familiarization session one to account for circadian rhythmicity (Teo,

134 McGuigan, \& Newton, 2011). Participants were asked to maintain their normal

135 physical activity level and nutritional habits but refrain from strength training or taking

136 any ergogenic aid throughout involvement in this study.

138 Participants

139 A power analysis program (G*Power, 3.1) was used to generate the optimal sample 140 size a priori using the guidance procedure by Faul, Erdfelder, Buchner, and Lang 141 (2009). Type I error for two tailed test and power were inputted as per conventional 142 levels (5\% for type I error and $80 \%$ for power) as described by Charles, Giraudeau, 143 Dechartres, Baron, and Ravaud (2009). The priori power analysis revealed a required 144 participant group of 42 and critical $t$ value of 2.02. Forty-two strength trained males 145 volunteered for participation (age: $21.4 \pm 4.5$ years, height: $1.86 \pm 0.06 \mathrm{~m}$, mass: $14693.5 \pm 12.4 \mathrm{~kg}$, strength training experience: $4.1 \pm 1.8$ years). Eligibility for participation 147 required greater than six months' experience in strength training and previously 148 experience in $1 \mathrm{RM}$ strength testing using the squat exercise. Ethical approval was 149 provided by the University institutional review board (Ulster University), and all 150 athletes provided written informed consent. All procedures within this investigation 151 conformed to the Declaration of Helsinki. All 42 participants remained within the 152 study group until familiarisation session 3, at which point 39 completed. Thirty-eight 153 participants completed the first testing session with 36 completing the retest and the 154 1RM testing. Six participants were unable to attend testing at the specific times to 
155 maintain circadian rhythmicity and were withdrawn from further involvement. In total,

156 the completion rate of the study was $85.7 \%$ with 36 completed participants' data used

157 for further analysis.

158

159 Procedures

160 Warm up

161 A standardized warm-up comprising five minutes of easy jogging followed by

162 dynamic preparatory movements such as squatting and lunging was undertaken by all

163 participants before isometric and $1 \mathrm{RM}$ squat testing. In preparation for isometric squat

164 tests, participants completed warm-up repetitions at self-determined estimated $75 \%$

165 and $90 \%$ of maximal effort prior to maximal testing. Prior to maximal 1RM squat

166 efforts to ninety degrees of knee flexion angle, participants completed 3 repetitions at

$16750 \%, 2$ at $80 \%$, and 1 at $90 \%$ of self-estimated 1RM.

169 Isometric squat

170 Isometric squat was assessed at a knee angle of $90^{\circ}\left(\mathrm{IS}^{90}\right)$ using a custom isometric

171 rack (Samson Equipment Inc, NM, USA) with adjustable settings to the nearest 2.5

$172 \mathrm{~cm}$ of vertical displacement. The knee angle was chosen as this approximately reflects

173 the sticking point during the squat exercise (Bazyler, Sato, Wassinger, Lamont, \&

174 Stone, 2014). All participants performed the test at the same relative knee angle,

175 measured using a handheld goniometer (66fit Ltd Lincolnshire, UK) by the lead

176 investigator. The isometric rack was positioned directly over two force plates (Kistler

177 type 9286BA, Winterthur, Switzerland) connected to an A/D converter (Kistler type

178 5691A1, Winterthur, Switzerland). The desired position for testing required

179 participants to stand on the force plate with their feet approximately shoulder width 
180 apart, trunk near-vertical, and the immoveable horizontal bar placed above the

181 posterior deltoids at the base of the neck. This position was established before each

182 trial, with the joint angle confirmed using goniometry. Participants' stance widths

183 were monitored using a standard measuring tape to ensure consistency between trials.

184 Participants were advised to maintain a constant and minimal pre-tension until the

185 tester gave verbal instruction, "2, 1, GO” upon which participants were cued to "push

186 against the ground as hard and as fast as possible". This external focus of attention has

187 previously been reported to optimize peak force output (Halperin, Williams, Martin,

188 \& Chapman, 2016). All participants were given verbal encouragement during each

189 trial. Temporal and vertical ground reaction force $\left(F_{\mathrm{z}}\right)$ data were collected at a

190 sampling frequency of $1000 \mathrm{~Hz}$ for a five second sampling period using Bioware ${ }^{\circledR}$

191 software (Version 5.1, Type 2812A). Trials were terminated when a plateau in the

192 force time trace was visually observed (Bazyler et al., 2014). The force plate was

193 zeroed immediately before each trial and sampling began on the verbal command.

194 Each participant completed two maximal effort trials with three minutes of passive

195 rest in between with the average of both trials used for further analysis.

197 IRM squat

198 The $1 \mathrm{RM}$ squat to a knee flexion angle of $90^{\circ}$ was performed according to the exercise

199 technique outlined by Chandler (1991) using a standard $20 \mathrm{~kg}$ Olympic barbell and 200 plates (Eleiko AB, Halmstad, Sweden) for loading. Participants were instructed to

201 adopt a shoulder width stance in keeping with their normal squat stance, descend in a

202 controlled manner, avoid bouncing at the bottom positon, maintain as near a vertical

203 torso as possible and feet always flat on the ground. Each 1RM trial was performed to 204 an adjustable metal box placed directly at the heels of the participant marked with 
205 athletic tape to ensure consistency in the horizontal displacement from the box and

206 enabled kinesthetic feedback to standardize the vertical displacement. Participants

207 were not permitted to pause or sit on the box. Each trial was visually monitored by the

208 lead investigator to ensure appropriate technique was maintained and the required

209 eccentric phase displacement was satisfied. Verbal encouragement was provided

210 throughout maximal testing. Following the last warm-up effort, participants were

211 instructed to progressively increase bar load in 1.25 to $5 \mathrm{~kg}$ increments per trial based

212 on their perception of effort until a maximum load was lifted. Participants were

213 permitted to repeat any failed lifts on one occasion only. For all squat trials a linear

214 position transducer (GymAware. Kinetic Performance Technologies, Canberra,

215 Australia) was attached to one side of the barbell to measure bar velocity and

216 displacement which was subsequently analyzed using custom software (GymAware

217 Version 3.13, Kinetic Performance Technologies). Mean concentric velocity was

218 assessed and used for feedback to participants after each trial to adjust bar loading

219 based on the critical velocity to successfully complete a 1RM trial (Loturco et al.,

220 2016). This variable has a coefficient of variation (CV) of $0.57 \%$ when assessing the

221 1RM squat (Sanchez-Medina \& Gonzalez-Badillo, 2011).

\section{Statistical analysis}

224 Prior to analysis data were visually inspected for normality. Box plots of all dependent 225 variables were inspected with no data outliers detected in test-retest time points. A 226 Shapiro-Wilks normality test assessed the distribution of the data with Levene's test 227 checking the homogeneity of variance. Stability reliability was assessed using a Bland 228 Altman analysis (Bland \& Altman, 1986) to determine the level of agreement between 229 test-retest measures and examine proportional bias. Intraclass correlation coefficients 
230 (ICC; 3,1) and their 95\% confidence intervals (CI), standard error of measurement 231 (SEM), and coefficient of variation (CV) were calculated on test-retest data. ICC was 232 interpreted using the criteria of Cortina (1993), whereby ICC $\geq 0.80$ is highly reliable.

233 SDD was calculated to enable interpretation of performance change over time for this

234 test. The equations used within this study were; $\boldsymbol{S E} \boldsymbol{M}=S D \times \sqrt{1}-I C C$, $235 \boldsymbol{S D D}=1.96 \times \sqrt{2} \times S E M$ (Beckerman et al., 2001; Weir, 2005). A general linear 236 model repeated measures ANOVA was used to examine the impact of familiarization 237 on kinetic performance variables across the five testing sessions. Mauchly's test of 238 sphericity was applied and if violated, the Greenhouse-Geisser correction factor was 239 used. Where appropriate, post-hoc analyses of significant effects were performed 240 using the Huynh-Feldt correction method. Independent $t$ tests were used to assess the 241 difference between strong and weak groups, determined by percentile division of the 242 total sampled participants. Strong participants were identified as the top $25 \%$ with 243 weaker participants defined within the bottom 25\% (Bailey et al., 2015a; Bailey, Sato, 244 Burnett, \& Stone, 2015b). This approach was repeated for $\operatorname{IS}^{90}$ peak, net and relative 245 force variables independently as participants may have a high level of absolute 246 strength but not necessarily a high level of relative strength due to effects of body mass 247 (Folland, Mc Cauley, \& Williams, 2008). Effect size (ES) was calculated by dividing 248 the between group difference by the pooled standard deviation to determine the 249 magnitude of difference between groups and classified as trivial $(<0.2)$, small $(0.2-$ 250 0.6), moderate $(0.6-1.2)$, large $(1.2-2.0)$, and very large $(2.0-4.0)$ (Hopkins, 251 Marshall, Batterham, \& Hanin, 2009). Statistical significance was set at $P \leq 0.05$. 252 Pearson's correlation assessed the relationship between IS $^{90}$ kinetic variables and 1RM 253 squat performance using the previous discussed thresholds (Hopkins, 2002). All 254 statistical calculations were performed using IBM SPSS Statistics 22 software (SPSS 
255 Inc., Chicago, IL, USA).

256

257 Results

258 Shapiro-Wilk's test revealed all IS ${ }^{90} \& 1 \mathrm{RM}$ variables were normally distributed.

259 Repeated measures ANOVA showed that Mauchly's test of sphericity was violated $260\left(\chi^{2}(9)=19.13, p=.24 ; \chi^{2}(9)=19.34, p=.23 ; \chi^{2}(9)=17.27, p=.45\right)$ for IS $^{90}$ peak

261 net and relative force variables respectively. Degrees of freedom were adjusted using 262 the Huynh-Feldt correction. A significant main effect was found across testing time 263 points, $F(3.68,128.7)=9.23, p<.001$. Bonferroni post hoc comparisons revealed 264 significant increases in peak force, net force and relative force between familiarization 2651 to 3 , and between familiarization 2 to $3(p \leq .002)$. Non-significant differences were 266 found between familiarization 3 to test session, and between test to retest sessions. 267 Statistics provided in table 1 and figure 1.

268 ****TABLE 1 ABOUT HERE*****

$269 * * * *$ FIGURE 1 NEAR HERE $* * * *$

270 Test-retest IS $^{90}$ force variables were highly reliable (ICC $=.856-.910,95 \%$ CI $[.735$ 271 to .953$], \mathrm{CV}=3.78-6.11 \%)$. Standard error of measurement was $98.62 \mathrm{~N}, 97.53 \mathrm{~N}$, 272 and $1.04 \mathrm{~N} \cdot \mathrm{kg}^{-1}$ for peak, net and relative $\mathrm{IS}^{90}$ force variables respectively. Reliability 273 statistics provided in table 2.

274 ****TABLE 2 ABOUT HERE****

275 Bland Altman analysis showed in test-retest conditions, IS ${ }^{90}$ peak force had a bias of $276-14.98 \mathrm{~N}$ (precision -32.12 to 62.09 ; limits of agreement -257.93 to 287.9 ), IS $^{90}$ net 277 force had a bias of $-14.08 \mathrm{~N}$ (precision -32.64 to 60.81 ; limits of agreement -256.58 to 
278284.75 ) and $\mathrm{IS}^{90}$ relative force had a bias of $-.161 \mathrm{~N} \cdot \mathrm{kg}^{-1}$ (precision -.34 to .66 ; limits

****FIGURE 2, 3 \& 4 NEAR HERE****

282 IS $^{90}$ peak force demonstrated a significant large correlation with 1 RM load. IS ${ }^{90}$ net

283 force demonstrated a significant large correlation with 1RM load, and significant

284 moderate correlation with $1 \mathrm{RM}$ relative load. IS $^{90}$ relative force demonstrated a

285 significant large correlation with 1RM relative load. Correlation coefficients are 286 provided in table 2.

287 Levene's test for equality of variances was non-significant $(p=.083-.723)$, therefore 288 group variances were treated as equal for subsequent independent $t$ tests. Based on 289 IS $^{90}$ peak force (Strong $\geq 2689 \mathrm{~N} ;$ Weak $\leq 2276 \mathrm{~N}$ ), very large significant differences 290 were found between strong and weak groups for 1RM load $(p=.000, \mathrm{ES}=2.4)$ but 291 small non- significant between group differences in 1RM relative load $(p=.619$, ES

$292=.2$ ). Based on IS $^{90}$ net force (Strong $\geq 1771 \mathrm{~N} ;$ Weak $\left.\leq 1365 \mathrm{~N}\right)$, very large significant 293 differences were present between strong and weak groups for 1RM load $(p=.000$, ES $294=2.1)$ and large significant difference in $1 \mathrm{RM}$ relative load $(p=0.023, \mathrm{ES}=1.2)$. 295 Group splits based on $\mathrm{IS}^{90}$ relative force (Strong $\geq 29.6 \mathrm{~N} \cdot \mathrm{kg}^{-1}$; Weak $\leq 24.1 \mathrm{~N} \cdot \mathrm{kg}^{-1}$ ), 296 moderate significant differences were present between strong and weak groups for $2971 \mathrm{RM}$ load $(p=.03, \mathrm{ES}=1.1)$ and very large significant difference in $1 \mathrm{RM}$ relative 298 load $(p=0.000, \mathrm{ES}=2.7) .1 \mathrm{RM}$ mean concentric velocity for all participants was $2990.294 \pm 0.086 \mathrm{~m} / \mathrm{s}$. Trivial to small non-significant differences were found between 300 strong and weak groups in mean concentric velocity. Group comparisons presented in 301 table 3. 


\section{Discussion}

304 This study aimed to assess the stability reliability of the IS ${ }^{90}$ test having accounted for 305 familiarization. Calder and Gabriel (2007) suggest that intentional or unintentional

306 effects of familiarization are important to consider when interpreting studies assessing

307 reliability and responsiveness. Changes in force output during familiarization can be

308 influenced by multiple factors beyond true changes in muscle strength, such as

309 learning execution technique, tolerance of maximal loads, increased motor unit

310 recruitment (Amarante do Nascimento et al., 2013) and decreases in antagonist co-

311 contraction (Calder \& Gabriel, 2007). Notably, this study found participants with an

312 average strength training experience of 4.1 years required three familiarization

313 sessions prior to stabilization of effects. Prior investigations using isometric multi-

314 joint tests report a familiarization was undertaken before testing but neglect to

315 demonstrate the stabilization of learning effects prior to the assessment of reliability

316 (Bazyler et al., 2014; Haff, Ruben, Lider, Twine, \& Cormie, 2015). As such, observed

317 learning effects within this study are not comparable to previous studies although they

318 may be generalizable to similar strength trained populations. However, familiarization

319 effects during a 1RM squat test were found to stabilize after approximately three 320 sessions (Soares-Caldeira et al., 2009), corroborating with the findings in this study.

322 Very high to nearly perfect relative reliability was found for IS ${ }^{90}$ variables between 323 test and retest sessions. No systematic bias was found between test-retest sessions with 324 Bland-Altman analysis revealing no proportional bias exists between measures.

325 Stability reliability measures within this study are congruent with resistance strength 326 trained female participants (Palmer et al., 2017) assessed in isometric half squatting 
327 (ICC 0.84; CV 11.2\%). Furthermore, our findings agree with two previous studies

328 assessing isometric mid-thigh pulls which demonstrated very high to nearly perfect

329 stability reliability (ICC 0.86 ; CV $<7 \%$ ) in seventeen adolescent athletes (Thomas,

330 Dos'Santos, Comfort, \& Jones, 2017) and nearly perfect (ICC 0.96 ; CV < 4.3\%) in

331 fourteen male athletes (Thomas, Comfort, Chiang, \& Jones, 2015). Additionally, high

332 reliability found for IS ${ }^{90}$ variables in this study are comparable to the reliability (ICC

$333>$.969) reported for 1RM squat test (Comfort \& McMahon, 2015) and as stated in the

334 review by Pereira and Gomes (2003), ICC values ranging between .79 and .99 were

335 found dependent on gender and type of test. Overall, the findings of this study suggest

336 a high level of relative reliability and low level of absolute error associated with the

337 stability reliability of isometric squat testing. This provides evidence for the use of the

$338 \mathrm{IS}^{90}$ as a reliable monitoring tool, which is a key requirement to monitor training

339 effects over time (Atkinson \& Nevill, 1998).

341 The SDD was determined as $274 \mathrm{~N}, 270 \mathrm{~N}$, and $2.9 \mathrm{~N} \cdot \mathrm{kg}^{-1}$ for IS ${ }^{90}$ peak force, net

342 force and relative force respectively, corresponding to changes of $11 \%$ in peak, $17 \%$

343 in net and $11 \%$ in relative force required to demonstrate meaningful change beyond

344 the error of the test. Reported SDD for IMTP peak force in Dos'Santos et al. (2017)

345 was $9 \%$ which is comparable to our findings. However, both our findings and

346 Dos'Santos et al. (2017) demonstrate lower SDD than recently reported by Palmer et

347 al. (2017) of $\sim 30 \%$ for the isometric half squat or Thomas et al. (2017) of $28 \%$ in the

348 IMTP. The heterogeneity of participants in the above studies may explain the observed

349 variance between reported SDD. Our results reflect a larger cohort of strength trained

350 adult participants (males) than previously reported. The SDD of isometric force is

351 central in enabling the assessment of responsiveness of training interventions in future 
352 studies with comparable populations.

354 Results showed 1RM load has a significant correlation with $\mathrm{IS}^{90}$ peak force $(\mathrm{r}=.688)$

355 and $\mathrm{IS}^{90}$ net force $(\mathrm{r}=.616) .1 \mathrm{RM}$ relative load has a significant correlation with $\mathrm{IS}^{90}$

356 relative force $(r=.759)$ and significant correlation $\operatorname{IS}^{90}$ net force $(r=.419)$. The

357 strength of these relationships corroborates with previous reported correlations

358 between isometric squats with 1RM squat. Nuzzo, McBride, Cormie, and McCaulley

359 (2008) found large significant correlation $(r=.624)$ between IS ${ }^{140 \text { knee }}$ and $1 \mathrm{RM}^{70 \text { knee }}$,

360 with Blazevich, Gill, and Newton (2002) showing similar very large significant

361 correlation $(r=.77)$ between $\mathrm{IS}^{90}$ knee and $1 \mathrm{RM}^{110}$ knee . Bazyler et al. (2014)

362 demonstrated the effects of joint angle on the corresponding relationship with the 1RM

363 performance, where IS ${ }^{90}$ knee has a very large relationship $(r=.864)$ with 1 RM back

364 squat and $\mathrm{IS}^{120 \text { knee }}$ has a moderate relationship $(\mathrm{r}=.597)$. Such findings illustrate the

365 importance of testing angle selection and explains a proportion of variation amongst

366 correlational statistics between 1RM and IMJTs.

368 Strength of correlations between 1RM squat and isometric squat will largely be

369 affected by the technical skill and experience of the participants (Abernethy, Wilson,

370 \& Logan, 1995), as well as the utilization of the strength shortening cycle to contribute

371 to force expression in the 1RM (Baker, Wilson, \& Carlyon, 1994). It is therefore

372 unlikely a perfect correlation will exist between 1RM squat and isometric squat,

373 although we surmise that the concentric contraction force capacity would be nearly

374 perfectly correlated with isometric contraction force. Monitoring of concentric

375 contraction velocity within this study verified 1RM efforts were truly maximal $(0.294$

$376 \pm 0.086 \mathrm{~m} / \mathrm{s}$ for participants last successful effort) in corroboration with existing 
377 evidence (Loturco et al., 2016), allowing future comparisons to be made. The large to 378 very large correlations observed between IS ${ }^{90}$ and 1RM performance observed in this

379 study and consistently in other published work demonstrates appropriate criterion 380 validity for the IS ${ }^{90}$ to be used to evaluate strength performance instead of $1 \mathrm{RM}$ testing.

381 We subscribe to the viewpoint that testing angle is important to correspond to the range 382 of motion of the training exercise and the portion of the exercise where the sticking 383 region occurs (Blazevich et al., 2002).

385 Significantly higher isometric strength corresponds to greater jump performance 386 (Kraska et al., 2009; Secomb et al., 2016) and cycling performance (Stone et al., 2004) 387 compared to weaker participants. Thomas, Jones, et al. (2015) suggested that it is 388 unknown whether significant differences in relative isometric strength measurements 389 would transfer to relative dynamic strength, such as the 1RM back squat. In this study, 390 between group analysis showed IS $^{90}$ net force and relative force capacity successfully 391 discriminated between 1RM and relative 1RM performance. Furthermore, IS ${ }^{90}$ peak 392 force discriminated between 1RM load but not relative 1RM performance. These 393 results confirm that isometric relative strength does transfer as relative dynamic 394 strength in the population studied in this investigation. Overall, our findings support 395 the use of the $\mathrm{IS}^{90}$ as a valid tool for assessing strength capacity and present a case that 396 IS $^{90}$ does discriminate between dynamic strength capacity. With very large 397 relationships reported between IMJTs and 1RM performance (McGuigan, Winchester, 398 \& Erickson, 2006), Blazevich et al. (2002) reports IMJT measures could be used to 399 predict 1RM performance therefore enabling estimated training loads for dynamic 400 exercises. Research pertaining to predictive approaches may find strongest validity in 
401 isometric net and relative variables as these have discriminated most clearly within

402 this study between 1RM performance.

403

404 Conclusion

405 To achieve reliable isometric strength data, pre-testing practice sessions are required

406 to account for the effects of familiarization. Isometric squats require less repetitions

407 or time comparatively to traditional $1 \mathrm{RM}$ testing which enhances practicality and

408 implementation into athlete's schedules. Under test retest conditions this study has

409 demonstrated that the $\operatorname{IS}^{90}$ is highly reliable. When evaluating strength trained athletes,

$41011 \%$ increases in peak or relative force represent meaningful differences beyond the

411 error of the test. IS ${ }^{90}$ discriminates between strong and weak performers in the 1RM

412 squat and therefore can be used as an alternative method of evaluating strength beyond

413 the conventional 1RM method.

415 References

416 Abernethy, P., Wilson, G., \& Logan, P. (1995). Strength and power assessment -

417 issues, controversies and challenges. Sports Medicine, 19(6), 401-417.

418 Amarante do Nascimento, M., Januario, R. S. B., Gerage, A. M., Mayhew, J. L.,

419 Pina, F. L. C., \& Cyrino, E. S. (2013). Familiarization and Reliability of One

420 Repetition Maximum Strength Testing in Older Women. Journal of Strength

421 and Conditioning Research, 27(6), 1636-1642.

422 Appleby, B., Newton, R. U., \& Cormie, P. (2012). Changes in strength over a 2-year

423 period in professional rugby union players. Journal of strength and

$424 \quad$ conditioning research, 26(9), 2538-2546. 
425 Atkinson, G., \& Nevill, A. M. (1998). Statistical methods for assessing measurement 426 error (reliability) in variables relevant to sports medicine. Sports Medicine, 26(4), 217-238.

428 Bailey, C. A., Sato, K., Burnett, A., \& Stone, M. H. (2015a). Carry-over of force production symmetry in athletes of differing strength levels. Journal of Strength and Conditioning Research, 29(11), 3188-3196.

Bailey, C. A., Sato, K., Burnett, A., \& Stone, M. H. (2015b). Force-Production Asymmetry in Male and Female Athletes of Differing Strength Levels. International Journal of Sports Physiology and Performance, 10(4), 504-508.

Baker, D., Wilson, G., \& Carlyon, B. (1994). Generality versus specificity - a comparison of dynamic and isometric measures of strength and speedstrength. European Journal of Applied Physiology and Occupational 
450 Beckerman, H., Roebroeck, M. E., Lankhorst, G. J., Becher, J. G., Bezemer, P. D., \& Verbeek, A. L. M. (2001). Smallest real difference, a link between reproducibility and responsiveness. Quality of Life Research, 10(7), 571-578.

Bland, J. M., \& Altman, D. G. (1986). Statistical methods for assessing agreement between two methods of clinical measurement. Lancet, 1(8476), 307-310.

Blazevich, A. J., Gill, N., \& Newton, R. U. (2002). Reliability and validity of two isometric squat tests. Journal of Strength and Conditioning Research, 16(2), 298-304.

Brady, C. J., Harrison, A. J., Flanagan, E. P., Haff, G. G., \& Comyns, T. M. (2017).

A Comparison of the Isometric Mid-Thigh Pull and Isometric Squat: Intraday Reliability, Usefulness and the Magnitude of Difference Between Tests. Int, J. Sports Physiol Perform, Advance online publication. doi: 
475 Comfort, P., Jones, P. A., McMahon, J. J., \& Newton, R. (2015). Effect of knee and 476 trunk angle on kinetic variables during the isometric midthigh pull: test-retest 477 reliability. Int J Sports Physiol Perform, 10(1), 58-63.

478 Comfort, P., \& McMahon, J. J. (2015). Reliability of Maximal Back Squat and 479 Power Clean Performances in Inexperienced Athletes. J. Strength Cond Res, $480 \quad$ 29(11), 3089-3096.

481 Cortina, J. M. (1993). What is coefficient alpha? An examination of theory and 482 applications. Journal of Applied Psychology, 78(1), 98.

483 Davidson, M., \& Keating, J. (2014). Patient-reported outcome measures (PROMs): 484 how should I interpret reports of measurement properties? A practical guide 485 for clinicians and researchers who are not biostatisticians. British Journal of $486 \quad$ Sports Medicine, 48(9), 792-796.

487 Dos'Santos, T., Thomas, C., Comfort, P., McMahon, J.J., Jones, P.A.,, \& Oakley, N. 488 P., Young, A.L. (2017). Between-Session Reliability Of Isometric Mid-Thigh Pull Kinetics And Maximal Power Clean Performance In Male Youth Soccer

492 Drake, D., Kennedy, R., \& Wallace, E. (2017). The Validity and Responsiveness of 493 Isometric Lower Body Multi-Joint Tests of Muscular Strength: a Systematic 494 Review. Sports Medicine - Open, 3(1), 23.

495 Faul, F., Erdfelder, E., Buchner, A., \& Lang, A.-G. (2009). Statistical power 496 analyses using $\mathrm{G}^{*}$ Power 3.1: Tests for correlation and regression analyses. 497 Behavior research methods, 41(4), 1149-1160.

498 Folland, J. P., Mc Cauley, T. M., \& Williams, A. G. (2008). Allometric scaling of 499 strength measurements to body size. Eur J Appl Physiol, 102(6), 739-745. 
500 Haff, G. G., Ruben, R. P., Lider, J., Twine, C., \& Cormie, P. (2015). A comparison

501 of methods for determining the rate of force development during isometric

502 midthigh clean pulls. Journal of strength and conditioning research, 29(2),

$503 \quad 386-395$.

504 Halperin, I., Williams, K. J., Martin, D. T., \& Chapman, D. W. (2016). The effects of

505 attentional focusing instructions on force production during the isometric

$506 \quad$ midthigh pull. Journal of Strength and Conditioning Research, 30(4), 919-

$507 \quad 923$.

508 Hopkins, W. G. (2002). A new view of statistics, [Retrieved from:

$509 \quad$ http://sportsci.org/resource/stats/effectmag.html].

510 Hopkins, W. G. (2004). How to interpret changes in an athletic performance test.

$511 \quad$ Sportscience, $8(1), 1-7$.

512 Hopkins, W. G., Marshall, S. W., Batterham, A. M., \& Hanin, J. (2009). Progressive

513 statistics for studies in sports medicine and exercise science. Medicine and

$514 \quad$ Science in Sports and Exercise, 41(1), 3-12.

515 Jidovtseff, B., Harris, N. K., Crielaard, J. M., \& Cronin, J. B. (2011). Using the load-

516 velocity relationship for 1RM prediction. Journal of Strength and

$517 \quad$ Conditioning Research, 25(1), 267-270.

518 Kennedy, R. A., \& Drake, D. (2017). Dissociated time course of recovery between

519 strength and power after isoinertial resistance loading in rugby union players.

$520 \quad$ Journal of Strength and Conditioning Research, Advance online publication.

$521 \quad$ doi: $10.1519 /$ JSC.0000000000001821.

522 Kraska, J. M., Ramsey, M. W., Haff, G. G., Fethke, N., Sands, W. A., Stone, M. E.,

523 \& Stone, M. H. (2009). Relationship between strength characteristics and 
unweighted and weighted vertical jump height. Int J Sports Physiol Perform, 4(4), 461-473.

526 Loturco, I., Pereira, L., Abad, C. C. C., Gil, S., Kitamura, K., Kobal, R., \& Nakamura, F. Y. (2016). Using bar velocity to predict the maximum dynamic

530 Maffiuletti, N. A., Aagaard, P., Blazevich, A. J., Folland, J., Tillin, N., \& Duchateau, J. (2016). Rate of force development: physiological and methodological considerations. European Journal of Applied Physiology, 1-26.

McGuigan, M. R., Newton, M. J., Winchester, J. B., \& Nelson, A. G. (2010). Relationship between isometric and dynamic strength in recreationally trained men. Journal of Strength and Conditioning Research, 24(9), 25702573.

McGuigan, M. R., Winchester, J. B., \& Erickson, T. (2006). The importance of isometric maximum strength in college wrestlers. Journal of Sports Science and Medicine, 5, 108-113.

McMaster, D. T., Gill, N., Cronin, J., \& McGuigan, M. (2014). A brief review of strength and ballistic assessment methodologies in sport. Sports Medicine, 44(5), 603-623.

Nuzzo, J. L., McBride, J. M., Cormie, P., \& McCaulley, G. O. (2008). Relationship between countermovement jump performance and multijoint isometric and dynamic tests of strength. Journal of Strength and Conditioning Research, 22(3), 699-707.

547 Palmer, T. B., Pineda, J. G., \& Durham, R. M. (2017). Effects of Knee Position on 58 the Reliability and Production of Maximal and Rapid Strength Characteristics 
549 During an Isometric Squat Test. Journal of Applied Biomechanics, Advance $550 \quad$ online publication. doi: 10.1123/jab.2017-0213.

551 Pereira, M. I. R., \& Gomes, P. S. C. (2003). Muscular strength and endurance tests:

552 reliability and prediction of one repetition maximum-Review and new

$553 \quad$ evidences. Revista Brasileira de Medicina do Esporte, 9(5), 325-335.

554 Ploutz-Snyder, L. L., \& Giamis, E. L. (2001). Orientation and familiarization to 555 1RM strength testing in old and young women. Journal of Strength and $556 \quad$ Conditioning Research, 15(4), 519-523.

557 Ritti-Dias, R. M., Avelar, A., Salvador, E. P., \& Cyrino, E. S. (2011). Influence of 558 previous experience on resistance training on reliability of one-repetition 559 maximum test. Journal of Strength and Conditioning Research, 25(5), 1418$560 \quad 1422$.

561 Sanchez-Medina, L., \& Gonzalez-Badillo, J. J. (2011). Velocity loss as an indicator 562 of neuromuscular fatigue during resistance training. Med Sci Sports Exerc, $563 \quad 43(9), 1725-1734$.

564 Secomb, J. L., Nimphius, S., Farley, O. R., Lundgren, L., Tran, T. T., \& Sheppard, J. 565 M. (2016). Lower-Body Muscle Structure and Jump Performance of Stronger 566 and Weaker Surfing Athletes. Int J Sports Physiol Perform, 11(5), 652-657.

567 Soares-Caldeira, L. F., Ritti-Dias, R. M., Okuno, N. M., Cyrino, E. S., Gurjao, A. L. 568 D., \& Ploutz-Snyder, L. L. (2009). Familiarization indexes in sessions of 1569 RM tests in adult women. Journal of Strength and Conditioning Research, $570 \quad 23(7), 2039-2045$.

571 Stone, M. H., Sands, W. A., Carlock, J., Callan, S., Dickie, D., Daigle, K., . . . 572 Hartman, M. (2004). The importance of isometric maximum strength and 
peak rate of force development in sprint cycling. Journal of Strength and Conditioning Research, 18(4), 878-884.

575 Storey, A., Wong, S., Smith, H. K., \& Marshall, P. (2012). Divergent muscle functional and architectural responses to two successive high intensity resistance exercise sessions in competitive weightlifters and resistance trained adults. European Journal of Applied Physiology, 112(10), 3629-3639.

579 Suchomel, T. J., Nimphius, S., \& Stone, M. H. (2016). The importance of muscular strength in athletic performance. Sports Medicine, 46(10), 1419-1449.

Taylor, K.-L., Cronin, J., Gill, N. D., Chapman, D. W., \& Sheppard, J. (2010).

584 Teo, W. P., McGuigan, M. R., \& Newton, M. J. (2011). The effects of circadian rhythmicity of salivary cortisol and testosterone on maximal isometric force,

588 Terwee, C. B., Bot, S. D. M., de Boer, M. R., van der Windt, D. A. W. M., Knol, D. maximal dynamic force, and power output. . Journal of Strength and Conditioning Research, 25(6), 1538-1545. L., Dekker, J., . . . de Vet, H. C. W. (2007). Quality criteria were proposed for measurement properties of health status questionnaires. Journal of Clinical Epidemiology, 60(1), 34-42.

Thomas, C., Comfort, P., Chiang, C., \& Jones, P. A. (2015). Relationship between isometric mid thigh pull variables and sprint and change of direction performance in collegiate athletes. Journal of Trainology, 4(1), 6-10.

Thomas, C., Dos'Santos, T., Comfort, P., \& Jones, A. P. (2017). Between-session reliability of common strength and power related measures in adolescent athletes. Sports, 5(1). 
598 Thomas, C., Jones, P. A., Rothwell, J., Chiang, C. Y., \& Comfort, P. (2015). An investigation into the relationship between maximum isometric strength and

600 vertical jump performance. Journal of Strength and Conditioning Research,

601 $29(8), 2176-2185$.

602 Wang, R., Hoffman, J. R., Tanigawa, S., Miramonti, A. A., La Monica, M. B., 603 Beyer, K. S., . . . Jeffrey, S. R. (2016). Isometric mid-thigh pull correlates 604 with strength, sprint and agility performance in collegiate rugby union 605 players. Journal of Strength and Conditioning Research, 30(11), 3051-3056.

606 Weir, J. P. (2005). Quantifying test-retest reliability using the intraclass correlation 607 coefficient and the SEM. Journal of Strength and Conditioning Research, $608 \quad 19(1), 231-240$.

609

610

611

612

613

614

615

616

617 Figure 1.

618 Box plot for $\mathrm{IS}^{90}$ peak force across testing sessions.

$619 *$ indicates significant difference from familiarization session $1(p<.001) . \dagger$

620 indicates significant difference from familiarization session $2(p<.05)$.

621

622 Figure 2. 
623 Bland Altman plot for IS ${ }^{90}$ Peak Force. Solid line represents the mean difference;

624 dashed lines represent $95 \%$ limits of agreement.

625

626 Figure 3.

627 Bland Altman plot for IS ${ }^{90}$ Net Force. Solid line represents the mean difference;

628 dashed lines represent 95\% limits of agreement.

629

$630 \quad$ Figure 4.

631 Bland Altman plot for IS ${ }^{90}$ Relative Force. Solid line represents the mean difference;

632 dashed lines represent $95 \%$ limits of agreement.

633

634

635 
TABLE 1. Effects of familiarization on force variables

\begin{tabular}{|c|c|c|c|c|}
\hline Test session & $\begin{array}{r}\text { Familiariza } \\
\text { tion } 1 \text { - } 2\end{array}$ & $\begin{array}{r}\text { Familiariza } \\
\text { tion } 2 \text { - } 3\end{array}$ & $\begin{array}{l}\text { Familiariza } \\
\text { tion } 3 \text { - Test }\end{array}$ & $\begin{array}{l}\text { Test - } \\
\text { Retest }\end{array}$ \\
\hline$\Delta \mathrm{IS}^{90 \text { Peak }}$ force $(\mathrm{N})$ & 45.61 & $91.15^{*}$ & -38.42 & -14.98 \\
\hline SD & 145.5 & 133.1 & 138.7 & 139.2 \\
\hline$p$ & 0.683 & 0.002 & 1.00 & 1.00 \\
\hline Effect Size & -0.157 & -0.315 & 0.13 & 0.05 \\
\hline $\mathbf{C V}$ & 4.17 & 3.92 & 3.97 & 3.81 \\
\hline$\Delta \mathrm{IS}^{90}$ Net force $(\mathrm{N})$ & 45.34 & $92.19^{*}$ & -39.94 & -14.08 \\
\hline SD & 145.9 & 131.0 & 138.0 & 138.1 \\
\hline$p$ & 0.706 & 0.002 & 0.913 & 1.00 \\
\hline Effect Size & -0.191 & -0.378 & 0.16 & 0.054 \\
\hline $\mathbf{C V}$ & 6.52 & 6.00 & 6.30 & 6.11 \\
\hline$\Delta$ IS $^{90}$ Relative force $\left(N \cdot \mathrm{kg}^{-1}\right)$ & 0.536 & $1.03 *$ & -0.433 & -0.161 \\
\hline SD & 1.69 & 1.48 & 1.53 & 1.47 \\
\hline$p$ & 0.657 & 0.002 & 0.982 & 1.00 \\
\hline Effect Size & -0.182 & -0.319 & 0.127 & 0.046 \\
\hline $\mathrm{CV}$ & 4.23 & 3.72 & 3.97 & 3.78 \\
\hline
\end{tabular}

*represents a significant difference between testing time points

Abbreviations: $\mathrm{N}=$ newton; $\mathrm{N} \cdot \mathrm{kg}^{-1}=$ newton per kilogram of body mass; $\mathrm{SD}=$ standard deviation; $\mathrm{CV}=$ coefficient of variation 
TABLE 2. Between test reliability variables and correlations with 1 RM performance

\begin{tabular}{|c|c|c|c|c|c|c|c|c|}
\hline $\begin{array}{c}\text { Reliability } \\
\text { Variable }\end{array}$ & $\begin{array}{c}\text { Test Mean } \\
\quad \pm \text { SD }\end{array}$ & $\begin{array}{c}\text { Retest } \\
\text { Mean } \pm \text { SD }\end{array}$ & $\begin{array}{c}\text { ICC }(95 \% \\
\text { CI })\end{array}$ & $\begin{array}{c}\text { SEM }(95 \% \\
\text { CI) }\end{array}$ & $\mathrm{CV}$ & SDD (as \%) & $\begin{array}{l}\text { Correlation } \\
\text { with 1RM } \\
\text { Load lifted } \\
\quad(\mathrm{kg})\end{array}$ & $\begin{array}{c}\text { Correlation } \\
\text { with 1RM } \\
\text { Relative } \\
\text { strength } \\
\text { (kg/kg) }\end{array}$ \\
\hline $\begin{array}{l}\text { IS }^{90 \text { Peak }} \text { force } \\
\text { (N) }\end{array}$ & $\begin{array}{c}2509.72 \pm \\
287.19\end{array}$ & $\begin{array}{c}2494.74 \pm \\
294.42\end{array}$ & $\begin{array}{c}.885 \\
(.787, .940)\end{array}$ & $\begin{array}{c}98.62 \\
(71.1,126.1)\end{array}$ & 3.88 & $\begin{array}{l}273.35 \\
(10.92)\end{array}$ & $.688^{* *} *$ & 0.099 \\
\hline $\begin{array}{l}\text { IS }^{90} \text { Net force } \\
\text { (N) }\end{array}$ & $\begin{array}{c}1591.78 \pm \\
256.13\end{array}$ & $\begin{array}{c}1577.69 \pm \\
257.87\end{array}$ & $\begin{array}{c}.856 \\
(.735, .924)\end{array}$ & $\begin{array}{c}97.53 \\
(70.2,124.9)\end{array}$ & 6.11 & $\begin{array}{l}270.33 \\
(17.06)\end{array}$ & $.616^{* *}$ & $.419 * *$ \\
\hline $\begin{array}{l}\text { IS }^{90} \text { Relative } \\
\text { force }\left(\mathrm{N} \cdot \mathrm{kg}^{-1}\right)\end{array}$ & $27.1 \pm 3.53$ & $26.94 \pm 3.41$ & $\begin{array}{c}.910 \\
(.830, .953)\end{array}$ & $\begin{array}{c}1.04 \\
(-1.8,3.9)\end{array}$ & 3.78 & $2.88(10.67)$ & 0.244 & $.759 * *$ \\
\hline
\end{tabular}

*represents a significant correlation between variables, $p<.001$.

Abbreviations: $\mathrm{N}=$ newton; $\mathrm{N} \cdot \mathrm{kg}^{-1}=$ newton per kilogram of body mass; $\mathrm{SD}=$ standard deviation; $\mathrm{ICC}=$ intraclass correlation coefficient; $\mathrm{SEM}=$ standard error of measurement; $\mathrm{CV}=$ coefficient of variation; $\mathrm{SDD}=$ smallest detectible difference. 
TABLE 3. 1RM performance comparison based on IS ${ }^{90}$ determined strong and weak groups

\begin{tabular}{|c|c|c|c|c|c|c|}
\hline \multirow{2}{*}{ Grouping variable } & \multicolumn{2}{|c|}{$I^{90}$ Peak force (N) } & \multicolumn{2}{|c|}{$I^{90}$ Net force (N) } & \multicolumn{2}{|c|}{ IS ${ }^{90}$ Relative force $\left(\mathrm{N} \cdot \mathrm{kg}^{-1}\right)$} \\
\hline & 1RM Load (kg) & $\begin{array}{l}\text { Relative 1RM Load } \\
\qquad(\mathrm{kg} / \mathrm{kg})\end{array}$ & $\begin{array}{l}\text { 1RM Load } \\
\qquad(\mathrm{kg})\end{array}$ & $\begin{array}{c}\text { Relative 1RM Load } \\
\qquad(\mathrm{kg} / \mathrm{kg})\end{array}$ & $\begin{array}{l}\text { 1RM Load } \\
\qquad(\mathrm{kg})\end{array}$ & $\begin{array}{c}\text { Relative 1RM Load } \\
(\mathrm{kg} / \mathrm{kg})\end{array}$ \\
\hline Strong group $(n=9)$ & $195.8 \pm 15.41$ & $1.96 \pm .256$ & $195.6 \pm 15.7$ & $2.08 \pm .273$ & $182.8 \pm 16.41$ & $2.13 \pm .202$ \\
\hline Weak group $(\mathrm{n}=9)$ & $160 \pm 14.57$ & $1.90 \pm .184$ & $166.7 \pm 11.72$ & $1.79 \pm .209$ & $167.8 \pm 9.39$ & $1.66 \pm .146$ \\
\hline$p$ & 0.000 & 0.619 & 0.000 & 0.023 & 0.03 & 0.000 \\
\hline Effect size & 2.4 & 0.2 & 2.1 & 1.2 & 1.1 & 2.7 \\
\hline Effect size interpretation & Very large & Small & Very large & Large & Moderate & Very large \\
\hline
\end{tabular}

Abbreviations: $\mathrm{N}=$ newton; $\mathrm{N} \cdot \mathrm{kg}^{-1}=$ newton per kilogram of body mass; Strong and weak group data are presented as means $\pm \mathrm{SD}$. 


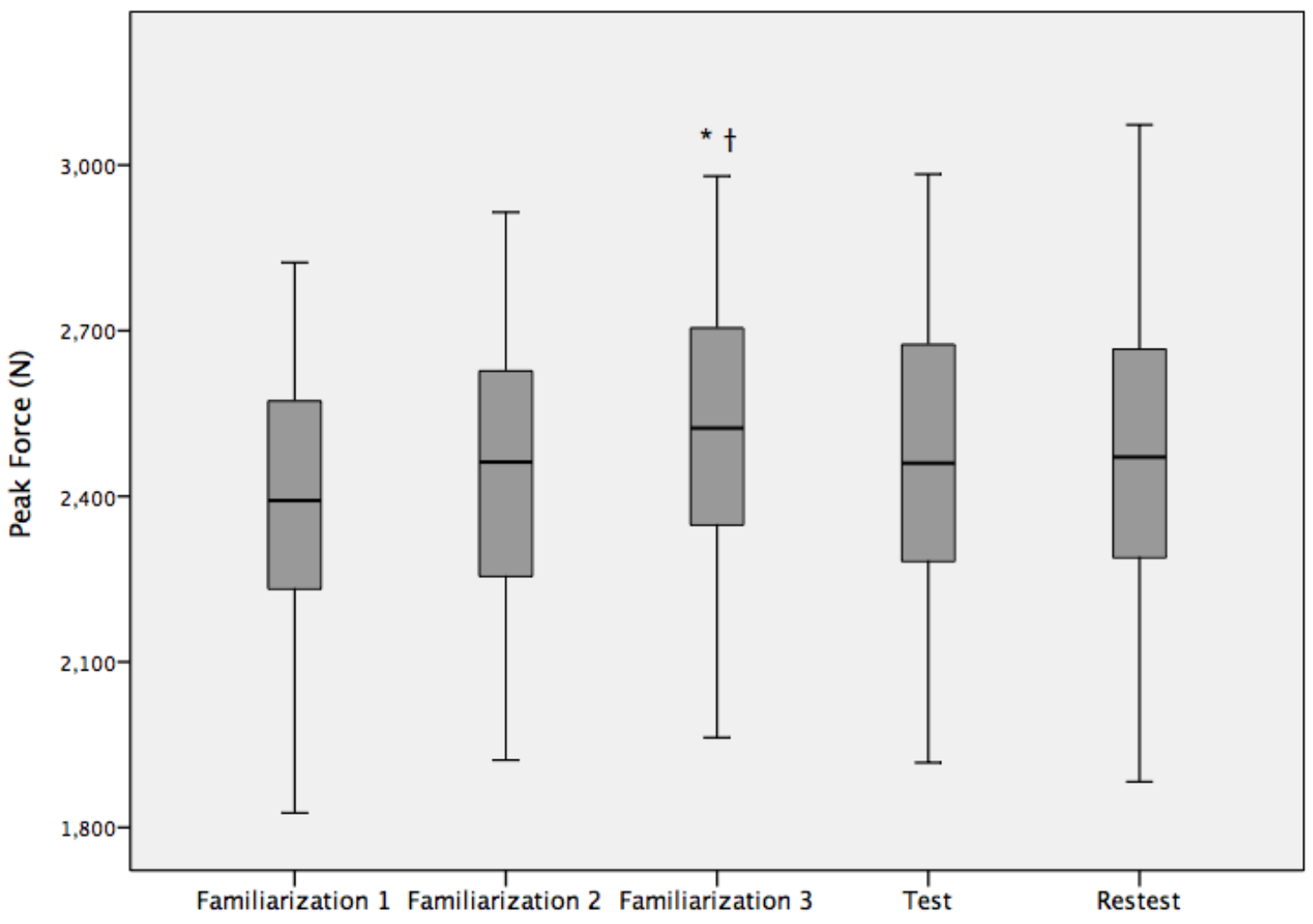

Figure 1.

Box plot for IS $^{90}$ peak force across testing sessions.

* indicates significant difference from familiarization session $1(p<.001) . \dagger$ indicates significant difference from familiarization session $2(p<.05)$. 


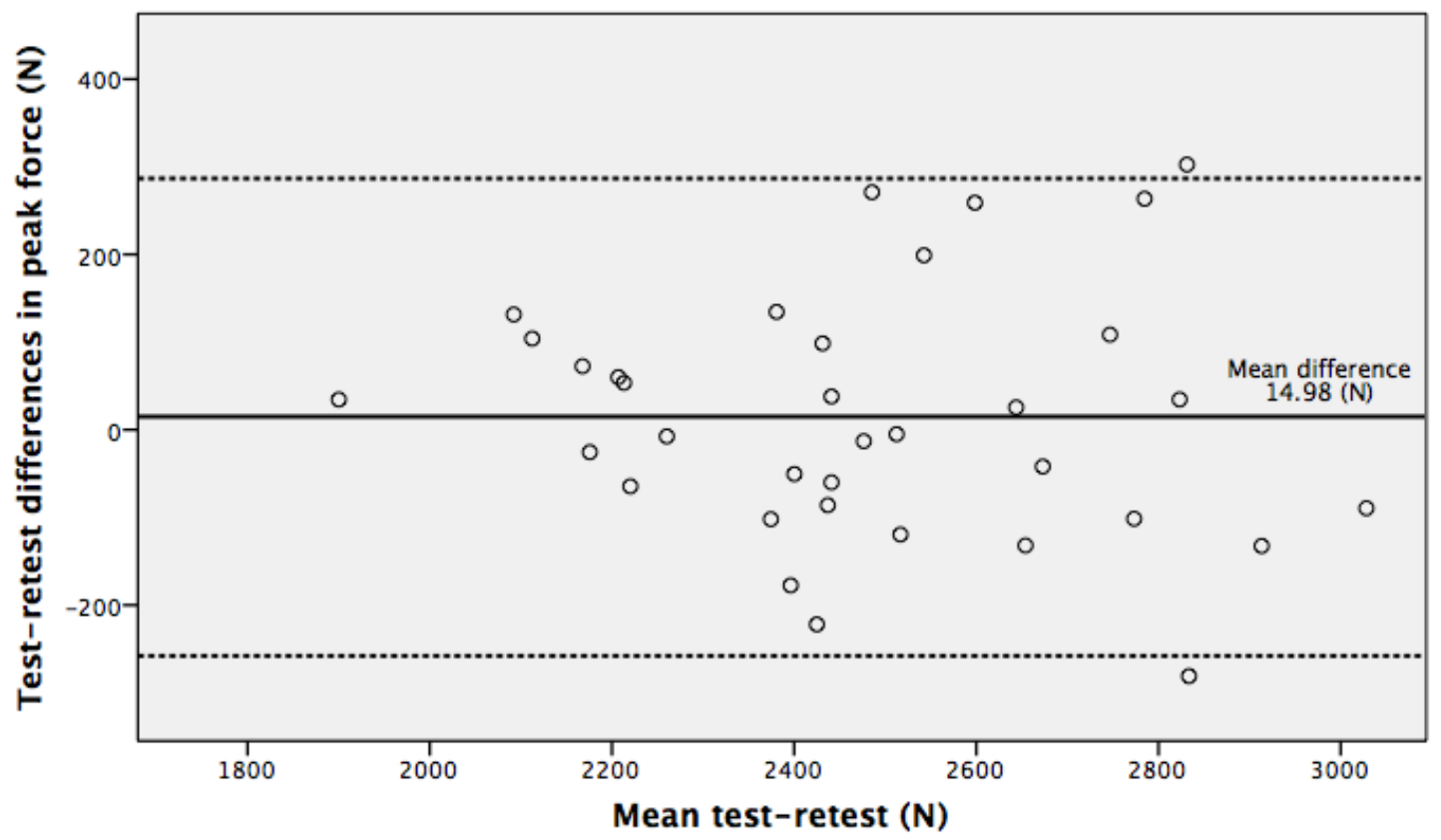

Figure 2.

Bland Altman plot for IS ${ }^{90}$ Peak Force. Solid line represents the mean difference; dashed lines represent $95 \%$ limits of agreement. 


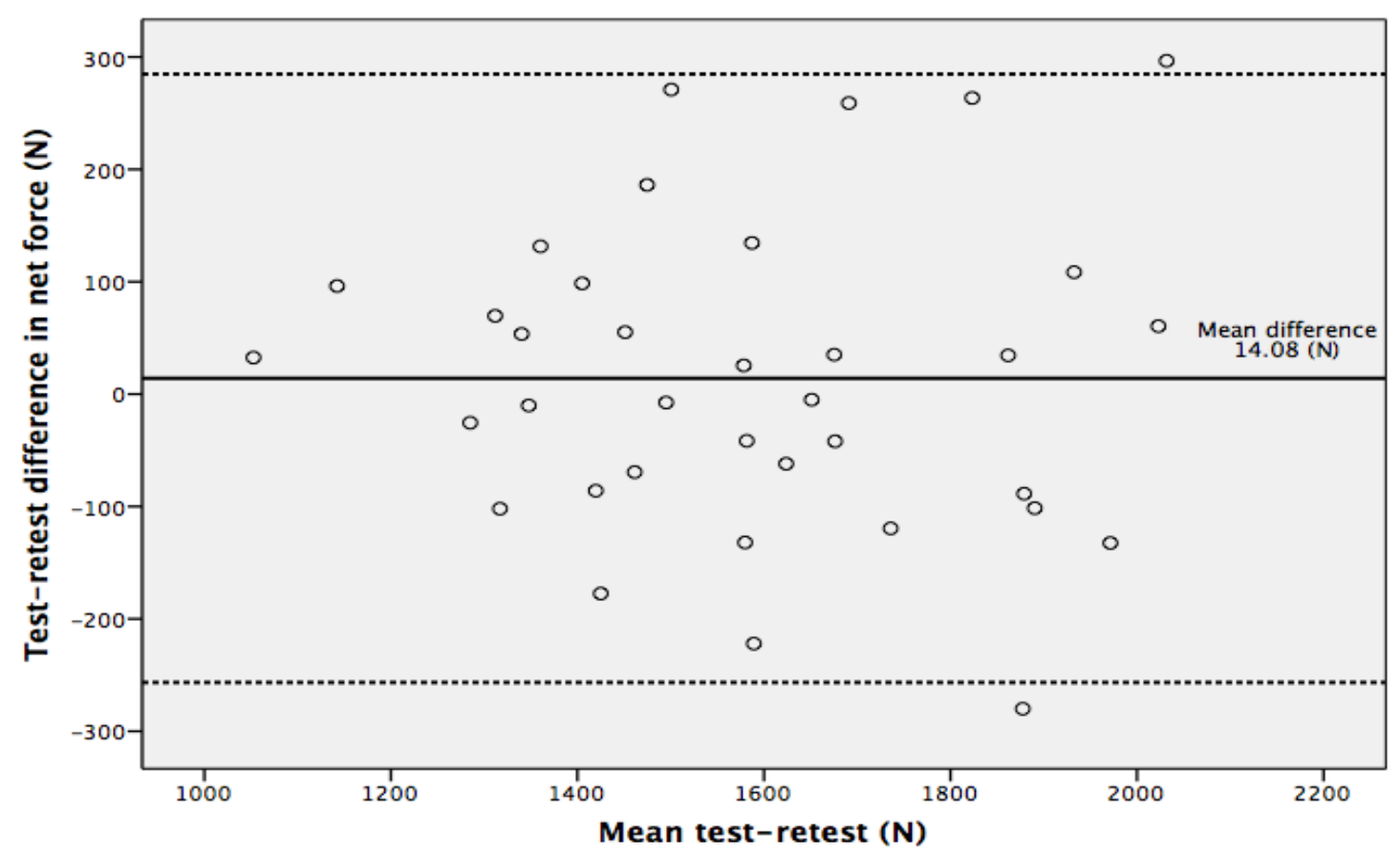

Figure 3.

Bland Altman plot for IS ${ }^{90}$ Net Force. Solid line represents the mean difference; dashed lines represent $95 \%$ limits of agreement. 


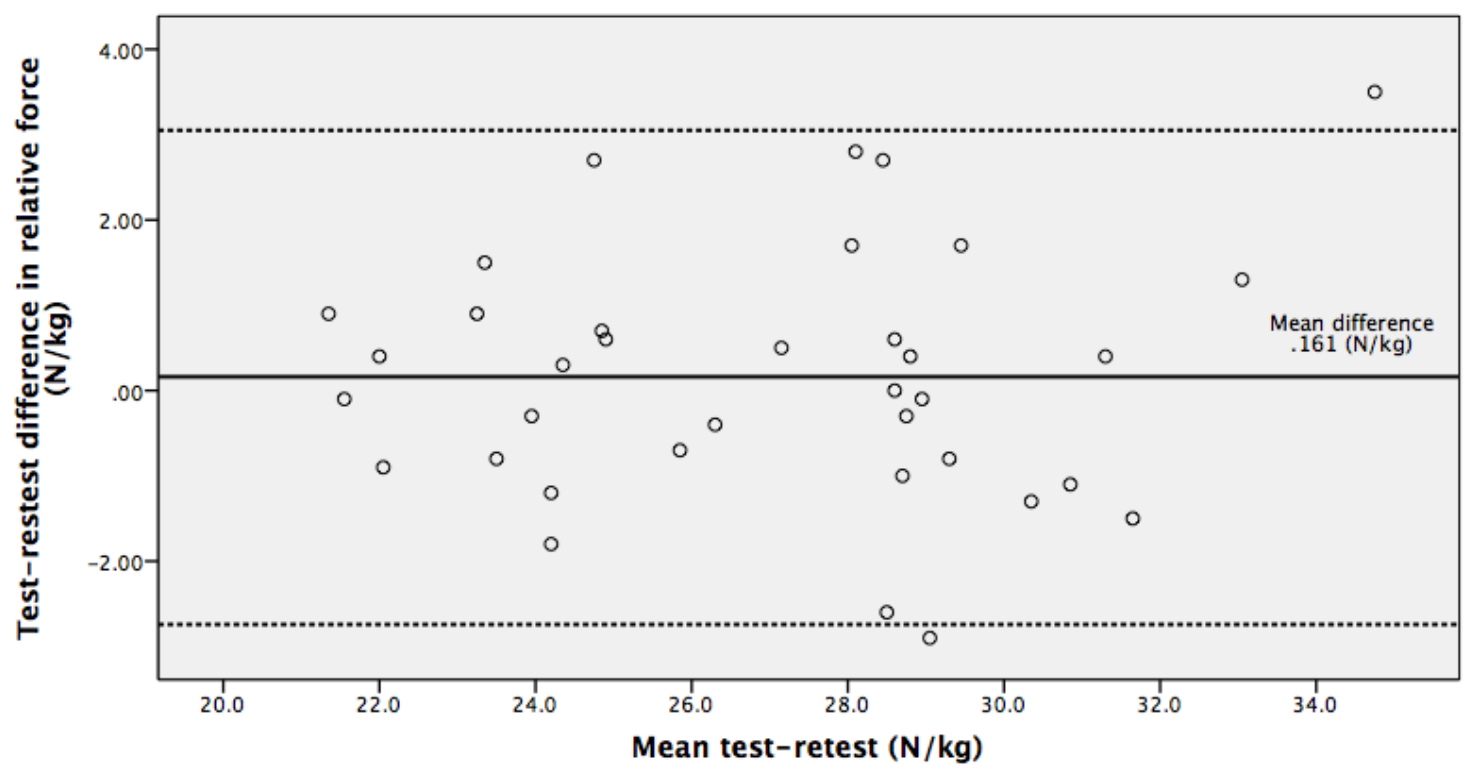

Figure 4.

Bland Altman plot for IS ${ }^{90}$ Relative Force. Solid line represents the mean difference; dashed lines represent $95 \%$ limits of agreement. 